\title{
Clinical and economic impact of current ALK rearrangement testing in Spain compared with a hypothetical no-testing scenario
}

Ernest Nadal ${ }^{1}$ (D), Dolores Bautista ${ }^{2}$, Luis Cabezón-Gutiérrez ${ }^{3}$, Ana Laura Ortega ${ }^{4}$, Héctor Torres ${ }^{5}$ (D), David Carcedo $^{6^{*}}$ (D, Lucía Ruiz de Alda ${ }^{7}$, J. Francisco Garcia ${ }^{7}$, Paula Vieitez ${ }^{7}$ and Federico Rojo ${ }^{8}$

\begin{abstract}
Background: Currently biomarkers play an essential role in diagnosis, treatment, and management of cancer. In non-small cell lung cancer (NSCLC) determination of biomarkers such as ALK, EGFR, ROS1 or PD-L1 is mandatory for an adequate treatment decision. The aim of this study is to determine the clinical and economic impact of current anaplastic lymphoma kinase testing scenario in Spain.

Methods: A joint model, composed by decision-tree and Markov models, was developed to estimate the long-term health outcomes and costs of NSCLC patients, by comparing the current testing scenario for ALK in Spain vs a hypothetical no-testing. The current distribution of testing strategies for ALK determination and their sensitivity and specificity data were obtained from the literature. Treatment allocation based on the molecular testing result were defined by a panel of Spanish experts. To assess long-term effects of each treatment, 3-states Markov models were developed, where progression-free survival and overall survival curves were extrapolated using exponential models. Medical direct costs (expressed in $€$, 2019) were included. A lifetime horizon was used and a discount rate of 3\% was applied for both costs and health effects. Several sensitivity analyses, both deterministic and probabilistic, were performed in order test the robustness of the analysis.
\end{abstract}

Results: We estimated a target population of 7628 NSCLC patients, including those with non-squamous histology and those with squamous carcinomas who were never smokers. Over the lifetime horizon, the current ALK testing scenario produced additional 5060 and 3906 life-years and quality-adjusted life-years (QALY), respectively, compared with the no-testing scenario. Total direct costs were increased up to $€ 51,319,053$ for testing scenario. The incremental cost-effectiveness ratio was 10,142 €/QALY. The sensitivity analyses carried out confirmed the robustness of the base-case results, being the treatment allocation and the test accuracy (sensitivity and specificity data) the key drivers of the model.

Conclusions: ALK testing in advanced NSCLC patients, non-squamous and never-smoker squamous, provides more than 3000 QALYs in Spain over a lifetime horizon. Comparing this gain in health outcomes with the incremental costs, the resulting incremental cost-effectiveness ratio reinforces that testing non-squamous and never-smoker squamous NSCLC is a cost-effective strategy in Spain.

\footnotetext{
* Correspondence: david.carcedo@hygeiaconsulting.com

${ }^{6}$ Hygeia Consulting S.A., Barcelona, Spain

Full list of author information is available at the end of the article
}

(c) The Author(s). 2021 Open Access This article is licensed under a Creative Commons Attribution 4.0 International License, which permits use, sharing, adaptation, distribution and reproduction in any medium or format, as long as you give appropriate credit to the original author(s) and the source, provide a link to the Creative Commons licence, and indicate if changes were made. The images or other third party material in this article are included in the article's Creative Commons licence, unless indicated otherwise in a credit line to the material. If material is not included in the article's Creative Commons licence and your intended use is not permitted by statutory regulation or exceeds the permitted use, you will need to obtain permission directly from the copyright holder. To view a copy of this licence, visit http://creativecommons.org/licenses/by/4.0/ The Creative Commons Public Domain Dedication waiver (http://creativecommons.org/publicdomain/zero/1.0/) applies to the data made available in this article, unless otherwise stated in a credit line to the data. 


\section{Background}

Lung cancer is the leading cause of cancer death worldwide and was responsible for the highest number of deaths from cancer in Spain in 2018, with 22,133 deaths $[1,2]$. Non-small cell lung cancer (NSCLC) accounts for 85-90\% of lung cancer cases [3]. NSCLC has various histological subtypes, of which adenocarcinoma is the most common. In this subtype of NSCLC, several oncogenic and actionable drivers have been described, such as rearrangement of the anaplastic lymphoma kinase $(A L K)$ gene, which is present in approximately $5 \%$ of cases of NSCLC [4]. Other actionable mutations have been detected in patients with NSCLC which affect the epidermal growth factor receptor (EGFR), BRAF, ERBB2, $M E T$ and gene fusions involving ROS1, RET or NTRK13 [5]. About 70\% of NSCLC patients have advanced disease at diagnosis, meaning they are not suitable for curative treatment [6]. The concept of personalized medicine came up with the identification of predictive biomarkers that enable the detection of patients who may obtain the greatest benefit with least associated toxicity from treatments such as chemotherapy or immunotherapy, or targeted therapy based on the individual tumor profile [7]. The detection of specific genomic alterations, such as $A L K$ gene rearrangement in lung cancer patients, has evolved, leading to improved new detection techniques, and is currently considered indispensable in NSCLC for the prognostic evaluation, clinical decision-making and appropriate treatment [8]. Therefore, molecular genotyping at the diagnosis of advanced NSCLC is critical, since target identification is absolutely essential to allow access to therapies with the best efficacy and safety profile [9].

Currently, various methods allow the detection of $A L K$ rearrangement in NSCLC, and the choice of assay depends on criteria such as personnel requirements, analytical parameters (sensitivity, specificity), associated costs, and others [10]. Molecular alterations in $A L K$ may be identified by fluorescent in situ hybridization (FISH), immunohistochemistry (IHC), real-time polymerase chain reaction (RT-PCR), and new molecular techniques as next-generation sequencing (NGS) and NanoString nCounter [11, 12].

For some years, FISH has been the reference standard for detecting tumors carrying $A L K$ rearrangement. However, growing evidence has shown that IHC testing is an efficient tool in the detection of $A L K$ rearrangement, and confirmation of positive results by FISH is no longer needed [10, 13].

The Spanish Society of Medical Oncology (SEOM) and the Spanish Society of Pathology (SEAP) have published common recommendations to guide biomarker testing in patients with advanced NSCLC according to current evidence. $A L K$ rearrangement should be tested in all patients with adenocarcinoma or non-squamous carcinoma, and also in squamous cell carcinoma in patients aged $<50$ years of age and/or with low or no tobacco use. According to guidelines for molecular diagnosis in advanced NSCLC patients, molecular testing of EGFR and BRAF mutations, ALK and ROS1 rearrangements and programmed death-ligand 1 (PD-L1) expression is considered mandatory $[3,14]$.

The main objective of this analysis was to quantify the clinical and economic impact of the current molecular testing scenario of NSCLC patients in Spain, focusing on the detection of $A L K$ rearrangement, and comparing it with a hypothetical no-testing scenario.

\section{Methods}

A joint model combining a decision-tree with Markov models was used to determine long-term health results and associated costs of the molecular testing scenario of NSCLC patients compared with a hypothetical notesting scenario in Spain, using Microsoft Excel 2010 (Fig. 1).

The decision-tree model considered four alternative strategies for ALK rearrangement determination: IHC, FISH, IHC followed by confirmation of positive results by FISH (reflex), and NGS. If the result was invalid, the test was repeated. If the result was interpretable, the model determined four possible results: true positive (TP), false positive (FP), true negative (TN), and false negative (FN). These four possibilities reflect the typical outcomes of a binary diagnostic test (positive or negative), the underlying prevalence of the biomarker of interest $(\mathrm{ALK}+)$, and the sensitivity and specificity of the test strategies [15]:

\footnotetext{
True positive: Prevalence * sensitivity

False positive: (1-prevalence) * (1-specificity)

True negative: (1-prevalence) * specificity

False negative: Prevalence * (1-sensitivity)
}

Based on the test results, a treatment was allocated and patients entered in the respective Markov model (in the no-testing scenario, patients enter directly into the non-targeted therapy Markov model), which was developed following an area under the curve structure with three health states: progression-free survival (PFS state), progressed-disease (PD state), and death state (absorbent state).

The Markov models considered monthly cycles, with a time horizon of 20 years (lifetime) and a discount rate of $3 \%$ for future costs and effects, as recommended by the guidelines for the evaluation of health technologies in Spain $[16,17]$.

The outcomes of the integrated model include life years (LY) and quality-adjusted life years (QALYs). Total costs (expressed in euros of 2020) were obtained from 


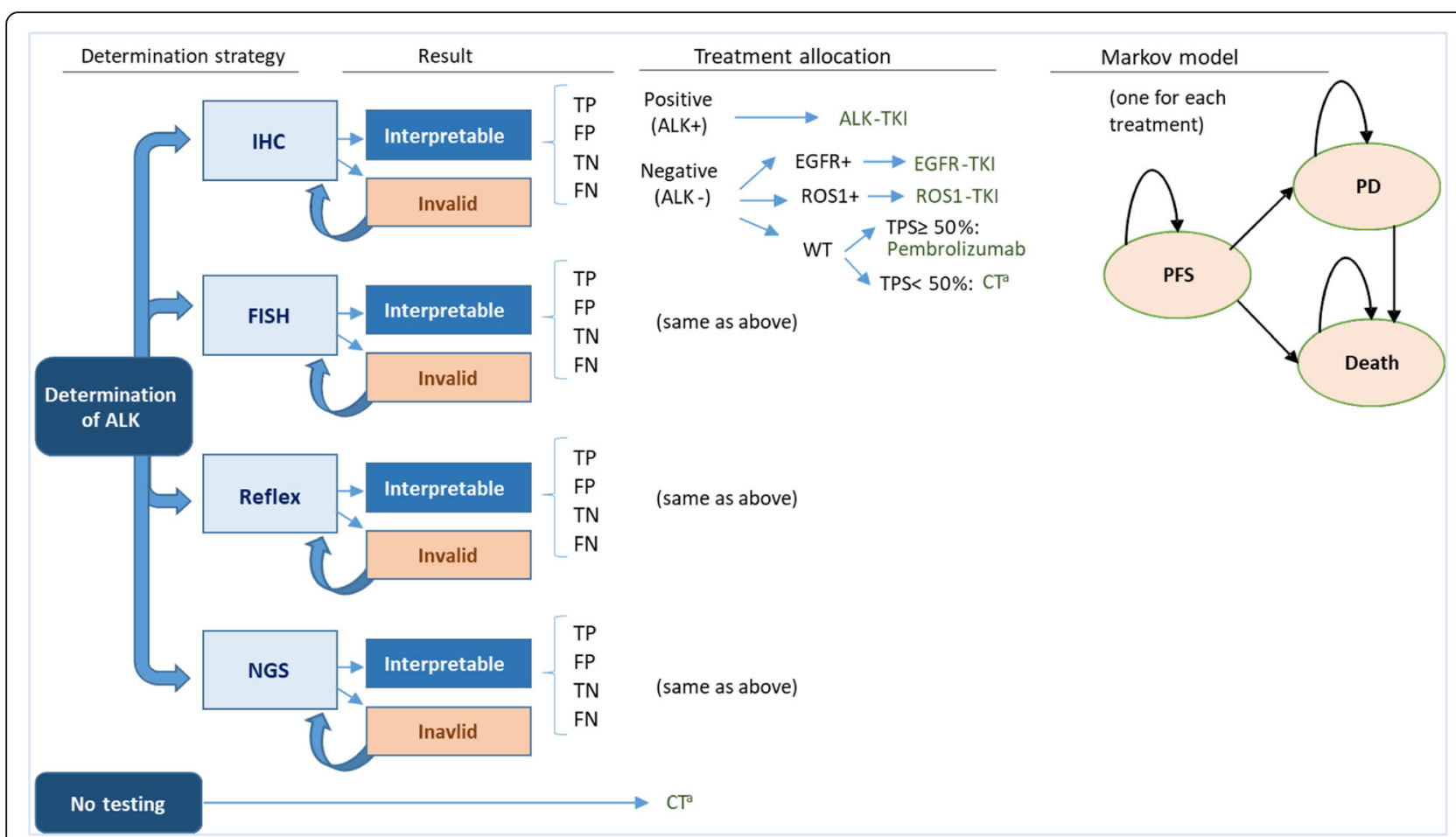

Fig. 1 Model diagram. ALK: anaplastic lymphoma kinase IHC: immunohistochemistry; FISH: fluorescent in situ hybridization; NGS: next-generation sequencing; TP: True positive; FP: false positive; TN: true negative; FN: false negative; EGFR:epidermal growth factor receptor; WT: wild-type; TPS: tumor proportion score TKI: tyrosine kinase inhibitors; PFS: progression-free survival PD: progressed-disease. ${ }^{a}$ Chemoterapy: cisplatin+pemetrexed; carbolplatin+paclitaxel+bevacizumab; cisplatin+pemetrexed+pembrolizumab

the health payer's perspective, thus, direct health costs were considered in the analysis.

A multidisciplinary group of oncologists and pathologists, who are authors of this article, validated the included parameters and assumptions made, as well as the clinical feasibility of the results.

\section{Target population}

A hypothetical cohort of patients with advanced or metastatic NSCLC, who were candidates for first-line treatment according to the molecular diagnosis, was included in the model. Following the current clinical guidelines for molecular diagnosis in lung cancer [14], both patients with non-squamous histology and those with squamous NSCLC who were never smokers were considered. Table 1 shows the estimation of the target population based on the literature [3, 18-22].

\section{Decision-tree parameters}

Table 2 lists all inputs specific to the decision-tree model.

Current distribution in Spain of the four ALK determination strategies included in the model (Fig. 1) was obtained from the analysis of the LungPath

Table 1 Estimated target population

\begin{tabular}{|c|c|c|c|c|}
\hline & & $\%$ & Reference & $\mathbf{N}$ \\
\hline 1 & Patients with lung cancer in 2020 & & (18) & 28,475 \\
\hline 2 & Patients with NSCLC & $85.0 \%$ & (3) & 24,204 \\
\hline 3 & Stage VI in samples of NSCLC patients & $54.5 \%$ & (19) & 13,191 \\
\hline 4 & Patients with stage IV NSCLC non-squamous subtype & $66.9 \%$ & (20) & 8825 \\
\hline 5 & Patients with stage IV NSCLC squamous subtype & $33.1 \%$ & $(20)$ & 4366 \\
\hline 6 & Patients with stage IV NSCLC squamous subtype, never smokers & $16.0 \%$ & (21) & 699 \\
\hline 7 & Candidate for ALK rearrangement diagnosis (steps $4+6$ ) & & & 9523 \\
\hline 8 & Patients finally tested for ALK (testing rate) & $80.1 \%$ & $(22)$ & 7628 \\
\hline
\end{tabular}

NSCLC Non-small cell lung cancer, ALK anaplastic lymphoma kinase 
Table 2 Summary of decision-tree inputs

\begin{tabular}{|c|c|c|}
\hline & Input & Reference \\
\hline \multicolumn{3}{|l|}{ ALK determination strategies } \\
\hline $\mathrm{IHC}$ & $37.2 \%$ & {$[18]$} \\
\hline FISH & $11.6 \%$ & {$[18]$} \\
\hline Reflex & $46.5 \%$ & {$[18]$} \\
\hline NGS & $4.7 \%$ & {$[18]$} \\
\hline \multicolumn{3}{|l|}{ Positivity rate in selected biomarkers } \\
\hline ALK+ & $3.4 \%$ & {$[18]$} \\
\hline EGFR+ & $13.6 \%$ & [18] \\
\hline ROS1+ & $2 \%$ & {$[18]$} \\
\hline PD-L1 $\geq 50 \%$ & $33 \%$ & {$[18]$} \\
\hline \multicolumn{3}{|l|}{ Percentage of invalid results } \\
\hline With $\mathrm{IHC}$ or FISH & $2.6 \%$ & {$[18]$} \\
\hline With NGS & $3.4 \%$ & [19] \\
\hline \multicolumn{3}{|l|}{ Rebiopsy } \\
\hline Probability of rebiopsy if invalid & $77.1 \%$ & {$[20]$} \\
\hline \multicolumn{3}{|l|}{ Specificity and sensitivity } \\
\hline $\mathrm{IHC}$ & $97.9 \%$ / 96.8\% & {$[21]$} \\
\hline FISH & $99.8 \%$ / 90.9\% & {$[22]$} \\
\hline NGS & $100 \%$ & Assumption $^{\mathrm{a}}$ \\
\hline
\end{tabular}

ALK anaplastic lymphoma kinase, IHC immunohistochemistry, FISH fluorescent in situ hybridization, NGS next-generation sequencing, EGFR epidermal growth factor receptor

${ }^{a}$ Considered the gold standard in the determination of $A L K$

database, as was the prevalence of positive results for the biomarkers of interest (positivity rate) [22].

In some cases, due to a lack of sample material or insufficient tumour cell percentage, it was not possible to accurately determine the test result and it was considered invalid, being a rebiopsy necessary sometimes. It was considered that in $77.1 \%$ of the invalid results a rebiopsy was carried (especially when patients were asymptomatic) waiting for results before starting treatment [24]. In the remaining $22.9 \%$, chemotherapy was initiated without a molecular diagnosis result. It was assumed that the percentage of invalid results would be the same when the determination of ALK was made with IHC or FISH, but not with NGS, where the percentage of invalid tests may be higher [23].

The specificity and sensitivity parameters of each testing technique were obtained from Marchetti et al. for IHC [25] and for FISH [26]. The first article reports data from the European Quality Assessment in Italy, while the second analyzed 1031 samples using IHC, with FISH as the reference technique, and discrepancies analyzed by NGS. For NGS, $100 \%$ of specificity and sensitivity was assumed, as it is considered the gold standard in the determination of ALK.

The specific costs of the decision-tree were the costs of the tests used for molecular diagnosis and the cost of biopsy (applied when rebiopsy was required). The costs of the tests were agreed by the expert panel: $€ 60.28$ for IHC; $€ 111.36$ for FISH; $€ 475$ for NGS; $€ 165$ for the EGFR test; $€ 100$ for the ROS1 test; and $€ 130$ for the PD-L1 test. For the biopsy, a cost of $€ 411.22$ was considered [27].

Depending on the molecular testing result, a specific treatment was assigned (Fig. 1). Since the analysis is focused on ALK testing, when patients entered the Markov models, it was necessary to differentiate whether the positive result for ALK was a TP or a FP and whether the negative result was a TN or a FN. TP was differentiated from FP, as treatments targeting ALK (alectinib/crizotinib) are not effective in patients without ALK rearrangement, and therefore these treatments in patients who are FP for ALK provides almost no benefit. In the case of negative tests, it was assumed that in FN patients (who were ALK+ actually), the determination of EGFR and ROS1 would be negative, assuming that the concurrency of more than one mutation in ALK and EGFR or ROS1 is very infrequent [22].

\section{Markov model parameters}

Eleven possible first-line treatments were considered, allocated according to the molecular diagnosis, entered the Markov models (one for each treatment) (Table 3). The distribution of treatments within the same molecular target was established by the panel of experts, reflecting current clinical practice in Spain.

Since the time horizon of the analysis was longer than the observation periods in clinical trials, it was necessary to extrapolate PFS and overall survival (OS) data, to obtain curves that allow to model transition between

Table 3 Distribution of treatments according to molecular diagnosis

\begin{tabular}{|c|c|c|c|c|}
\hline \multirow{2}{*}{\multicolumn{2}{|c|}{$\begin{array}{l}\text { Molecular } \\
\text { diagnosis }\end{array}$}} & \multirow[t]{2}{*}{ Treatment } & \multicolumn{2}{|c|}{ Distribution } \\
\hline & & & $\overline{\mathrm{BC}}$ & SA \\
\hline \multirow{2}{*}{\multicolumn{2}{|c|}{ ALK+ }} & Alectinib & $89.38 \%$ & $80 \%$ \\
\hline & & Crizotinib & $10.63 \%$ & $20 \%$ \\
\hline \multirow{4}{*}{\multicolumn{2}{|c|}{ EGFR+ }} & Erlotinib & $15.0 \%$ & $0.0 \%$ \\
\hline & & Gefitinib & $30.0 \%$ & $30.0 \%$ \\
\hline & & Afatinib & $15.0 \%$ & $5.0 \%$ \\
\hline & & Osimertinib & $40.0 \%$ & $65.0 \%$ \\
\hline \multicolumn{2}{|c|}{ ROS1+ } & Crizotinib & $100 \%$ & $100 \%$ \\
\hline \multirow[t]{4}{*}{ WT } & TPS 50\% & Pembrolizumab & $100 \%$ & $100 \%$ \\
\hline & TPS $<50 \%$ & Cisp + pmtrx & $30.00 \%$ & $40.0 \%$ \\
\hline & & Carb + paclitx + bev & $10.00 \%$ & $5.0 \%$ \\
\hline & & Cisp + pmtrx + pembro & $60.00 \%$ & $55.0 \%$ \\
\hline
\end{tabular}

$A L K$ anaplastic lymphoma kinase, EGFR epidermal growth factor receptor, $W T$ wild-type, TPS tumor proportion score, Cisp cisplatin, Carb carboplatin, pmtrx pemetrexed, paclitx paclitaxel, bev bevacizumab, BC Base case, SA sensitivity analysis 
health states. In the absence of individualized patient data for each treatment, it was decided to use exponential models based on the median PFS and OS reported in the respective studies. In the recent update of the ALEX trial [28], used to obtain PFS and OS median for alectinib and crizotinib, median $O S$ in the alectinib group was not reached, so extrapolation curves were obtained from the cost-effectiveness model of alectinib (data on file). Median PFS and OS for EGFR-targeted therapies were obtained from the FLAURA study [29, 30], and for ROS1-targeted therapies from PROFILE 1001 [31]. For wild-type (WT) patients treated with pembrolizumab in monotherapy, median PFS and OS were obtained from KEYNOTE024 [32, 33], while from WT patients with tumor proportion score (TPS) $<50 \%$ median PFS and OS for the tree treatment strategies considered in the model were obtained from PARAMOUNT [34], Sandler et al. [35] and KEYNOTE-189 [36, 37].

Some adjustments had to be made in the PFS and OS exponential curves in the case of FP in ALK. The expert panel considered that most patients will have shown progression at the first follow-up visit and all of them will have progressed in the second visit. Based on this, a median of 2 months was assumed for the PFS in these patients, applying a stopping rule at 6 months (all patients progressed by then). Concerning OS, where there are more factors to consider, such as subsequent therapies, a median of 18 months was assumed.

The specific costs of the Markov models were the drug acquisition costs (both first-line and subsequent treatments) and the administration costs of intravenous treatments. Drug costs are expressed as the wholesale price considering the corresponding deductions according to Royal Decree-Law 08/2010 [38, 39]. For drugs where the dose depends on the patient characteristics, a mean body surface area of 1.81 and a mean weight of $72.885 \mathrm{~kg}$ was used [40]. Vial sharing for intravenous treatments was assumed.

Concerning intravenous administration costs, a cost of $€ 211$ was considered (corresponding to day hospital visit) [27].

The model also included the cost of subsequent treatments (once patients progressed after first-line treatment and transit to the PD state). To avoid uncertainty regarding subsequent treatments and simplifying the model, only second-line treatments were considered. The percentage of patients receiving an active secondline treatment or who would receive best supportive care (BSC) was determined by the panel of experts, and as was the selection of the most representative second-line treatment (based on the first-line treatments received). The median PFS for second-line treatments was obtained from the literature [41-47]. All these parameters of the subsequent treatments are shown in an additional file [see Additional file 1].

The model incorporated utility values of 0.814 for PFS state, and 0.725 and 0.470 for the PD state with and without active treatment, respectively [48].

\section{Sensitivity analysis}

To assess the uncertainty of some variables used in the analysis and to determine the robustness of the model and the results obtained, both deterministic and probabilistic sensitivity analyses (PSA) were performed.

\section{Scenario analysis}

Alternative scenarios to the base case were performed, modifying some assumptions, or exploring methodological alternatives.

- Target population scenarios: only patients with adenocarcinoma; and increasing the testing rate progressively (85\% year 2 and $90 \%$ year 3 ).

- Time horizon: 10, 5 and 3 years, instead of lifetime (fixed at 20 years).

- Decision-tree scenarios: sequential rather than parallel diagnoses, and scenarios reducing invalid tests in IHC and FISH to 1\% (not in NGS) and with $0 \%$ invalid tests in all options (IHC, FISH and NGS).

- Markov-model scenarios: alternative treatment allocation (Table 3), adjustments in the FP response for ALK (variations in PFS medians (1.5-3) and OS (15-21); and no stopping rule at 6 months), and without considering the cost of subsequent treatments.

\section{Univariate analysis (one-way sensitivity analysis)}

Some model variables were individually modified by $10 \%$ or $20 \%$ (depending on the uncertainty associated with the variable) with respect to the base case.

\section{Bivariate analysis}

Given the uncertainty associated with these variables, a specific analysis was performed where the sensitivity and specificity of IHC and FISH were simultaneously modified by $\pm 1 \%, \pm 2 \%, \pm 3 \%$, etc.

\section{PSA}

1000 simulations were performed using second-order Monte Carlo methodology, simultaneously modifying all model variables using a given distribution, in line with reported recommendations [49]. Utility values were modified using a beta distribution. For the body surface area and weight, the median PFS and OS, the positivity rate, the percentage of invalid results, and the probability of rebiopsy when results are invalid, a normal 
distribution was used. All unit costs were modified according to a gamma distribution.

\section{Results}

The costs and health outcomes obtained from the Markov models analyzed independently of the allocation between testing methods in the decision-tree, provided the mean cost as the mean QALYs per-patient according to the test result (Fig. 2). These results provide an assessment of costs and health outcomes per-patient, regardless of the technique used to obtain the TP, FP, TN and FN test outcome.

TP patients correctly treated with ALK-targeted therapies shown the best health outcomes, which also led to higher costs, as they spent more time in the PFS state while being treated with alectinib or crizotinib. FP patients had the worst health outcomes and the lowest cost, as they quickly progressed to second-line receiving few cycles of alectinib or crizotinib.

Table 4 lists the results of the base case, showing the total health outcomes and costs for the current testing scenario and the non-testing scenario, including the incremental results comparing both scenarios.

The current strategy of testing patients with advanced NSCLC provided a gain of 3907 QALYs compared with the no-testing scenario, over a 20-year time horizon. This also entailed higher costs, including those of the tests themselves, but mainly due to the cost of targeted treatments. The comparison of costs and health outcomes through the incremental cost-effectiveness ratio (ICER), shows that the current ALK testing strategy in Spain is cost-effective, as it was below the cost-effectiveness thresholds commonly considered in Spain $[50,51]$.

\section{Sensitivity analysis}

The target population scenarios affect only the absolute value of the results (in both scenarios compared), maintaining the ICER constant. If only patients with adenocarcinoma were tested, only 3620.06 QALYs would be gained (287 fewer QALYs gained than in the base case). In the scenario where the testing rate was increased up to $90 \%$ after 2 years, the gain in QALYs compared with the non-testing scenario would be 4389.48 QALYs (483 more than in the base case).

Shorting time horizon up to 10,5 and 3 years, increased the ICER to $€ 14,223$, $€ 16,360$, and $€ 17,275$ / QALY, respectively.

The decision-tree scenarios had a slight influence on the results, and only affected the current testing scenario (the non-testing scenario remained the same). A sequential instead of a parallel diagnosis slightly decreased the costs of the current testing scenario (€ -391,375), and the ICER was reduced to $€ 13,036 /$ QALY. Reducing the percentage of invalid tests also hardly impacted on the ICER ( $€ 13,139$ and $€ 13,140$ /QALY for the two scenarios posed, respectively).

The Markov model scenarios had the greatest influence on the base case results. When the allocation of treatments shown in Table 3 was modified, the ICER increased to $€ 24,660 / \mathrm{QALY}$, mainly due to the total cost for a lifetime horizon of the non-testing scenario being reduced from $€ 806,959,058$ to $€ 749,855,143$ $(€-57,103,915)$, while in the current testing scenario it was only reduced by $€ 6,911,633$. The adjustments in the response to FP for ALK only affected the current testing scenario, although the changes respect to the base case were minimal $( \pm 0.01 \%$ with respect to costs and QALYs). The ICER resulting from modifying the PFS

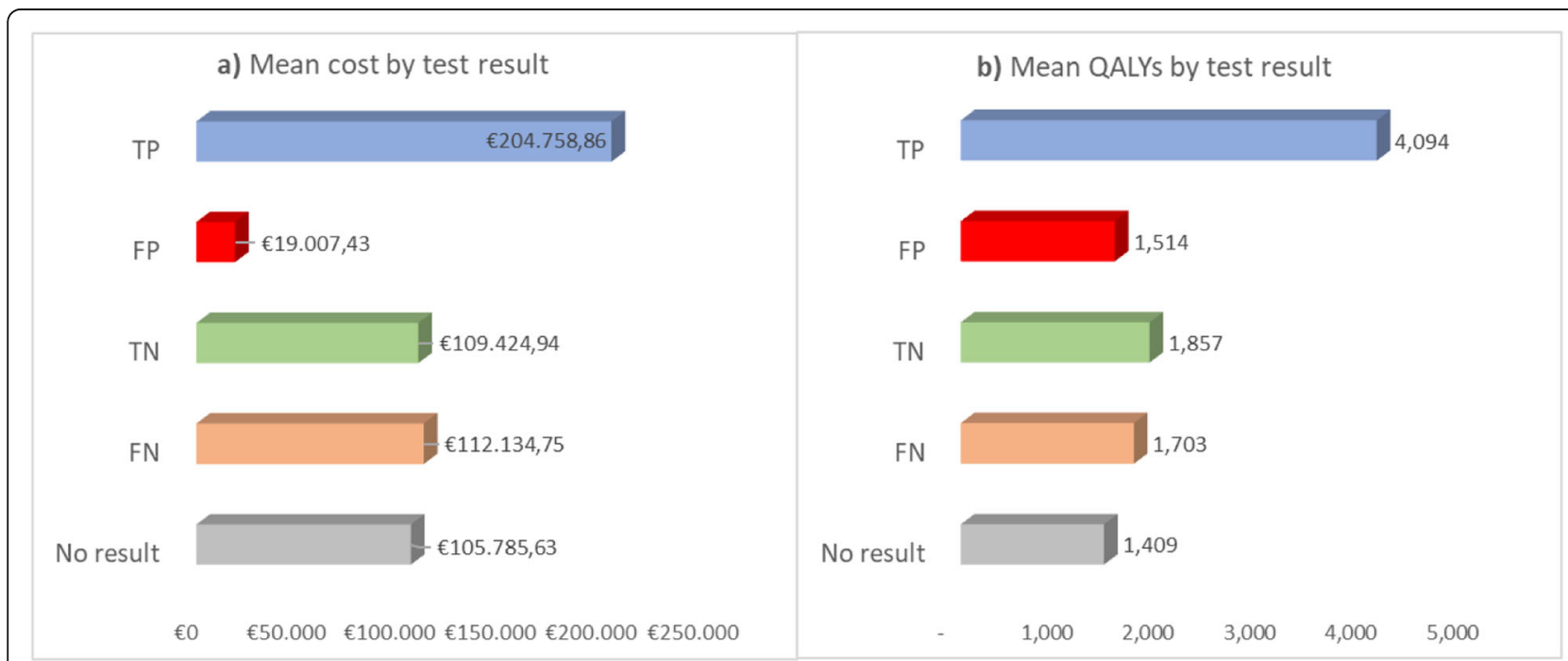

Fig. 2 Mean results per patient. TP: True positive; FP: false positive; TN: true negative; FN: false negative 
Table 4 Base case results

\begin{tabular}{|c|c|c|c|}
\hline & Current scenario tested & No-testing & Difference \\
\hline Cost of testing & $€ 3,613,701$ & $€ 0$ & $€+3,613,701$ \\
\hline Cost of treatment & $€ 854,664,411$ & $€ 806,959,058$ & $€+47,705,353$ \\
\hline Total costs & $€ 858,278,111$ & $€ 806,959,058$ & $€+51,319,053$ \\
\hline LY & $21.233,59$ & $16.173,45$ & +5060.14 \\
\hline QALYS & $14.654,68$ & $10.748,05$ & +3906.64 \\
\hline ICER (€/LY gained) & & & $€ 10,142 / \mathrm{LY}$ \\
\hline ICUR (€/QALY gained) & & & $€ 13,136 / \mathrm{QALY}$ \\
\hline
\end{tabular}

LY life years, QALY quality-adjusted life years, ICER incremental cost-effectiveness ratio, ICUR incremental cost-utility ratio

and OS in FP patients, or not considering the 6-months stopping rule were $€ 13,134, € 13,137$, and $€ 13,148$ / QALY, respectively. Not considering second-line treatments reduced the ICER to $€ 10,059 / \mathrm{QALY}$, due to a reduction of $€ 58,666,678$ and $€ 46,645,461$ in the total costs of the current and non-testing scenarios, respectively.

The results of the univariate analysis, where the impact of the extreme values of each variable on the base case incremental cost-utility ratio (ICUR) and are assessed, are represented by a tornado diagram in Fig. 3. Patient characteristics (mean weight and body surface area), discount rate (for both cost and effects), and prevalence of EGFR+ shown the greatest impact on base case results (Fig. 3a). The tornado diagram represented in Fig. 3b detailed the analysis of the second-line costs.

In the bivariate analysis, the specificity and sensitivity base case parameters are increased and decreased simultaneously, and Table 5 shows how the 3907 QALYs gained in the base case are modified accordingly. The gradient from green to red shows the difference from the base case.

Figure 4 shows the PSA results represented by an incremental cost-effectiveness plane. The means obtained from the 1000 simulations $(€+51,319,053$ and 3907 QALYs gained with respect to the non-testing scenario) are in line with the deterministic results in Table 4.

\section{Discussion}

In recent years there have been multiple changes in the approach to lung cancer treatment and, in particular, to NSCLC, including the identification of biomarkers that allow treatment selection in some subgroups of patients with advanced disease [52]. Deciding which biomarkers and which subgroup of patients should be tested is clinically relevant, and it must be assessed at diagnosis, since the first treatment a cancer patient receives should be the most effective according to their clinical and molecular features [52].

Specifically, the detection of $A L K$ rearrangements in patients with NSCLC provides unquestionable clinical benefits. A systematic review and meta-analysis by Elliott et al. [53] concluded that, ALK inhibitors improved PFS relative to chemotherapy. Also, treatment-related deaths were found to be infrequent among ALK-positive NSCL $\mathrm{C}$ patients [53]. Molecular testing for these rearrangements (along with molecular alterations in other biomarkers) is considered mandatory in all patients with non-squamous NSCLC or patients with squamous NSCLC younger than 50 years or with low tobacco exposure, according to the current clinical guidelines [14, 54, 55]. Next-generation ALK tyrosine kinase inhibitors (TKI) have generally replaced crizotinib, the firstgeneration TKI, as front-line treatments for patients with ALK-positive NSCLC [28]. Alectinib was associated with longer PFS and lower toxicity than crizotinib and showed activity against central nervous system (CNS) disease in patients with ALK-positive NSCLC [56].

Pathology departments must work in coordination with the other services involved in the diagnosis and treatment of NSCLC patients and are key to optimizing the available resources and the clinical management of these patients [52]. Therefore, to evaluate the efficiency of the management of patients with advanced NSCLC in Spain, a comprehensive approach to molecular diagnosis in conjunction with pharmacological treatment is essential.

Our study is the first one that uses this comprehensive approach to assess the long-term clinical and economic impact of the current molecular testing scenario in Spain. The Markov models allow the calculation of longterm costs, LYs, and QALYs for each treatment that is allocated based on the molecular result, and together with the positivity rate of each biomarker, the mean cost as the mean QALYs per patient were calculated. The TP patients provide, by far, the best health outcomes while the FP represented the worst health outcomes, therefore specificity and sensitivity have great importance. Bivariate analysis showed that when specificity and sensitivity were decreased equally (in the same percentage), gained QALYs were slightly lower with the decreased specificity than with the decreased sensitivity. Complementing the Markov models, the decision tree model allows to 
a) One-way sensitivy analysis results

\section{ICUR: $€ 13,136 /$ QALY base case}

Mean weight and body surface area
$€ 11.260$
$€ 15.394$

Discount rate, effects

$$
€ 10.741
$$

$€ 14.871$

Discount rate, costs

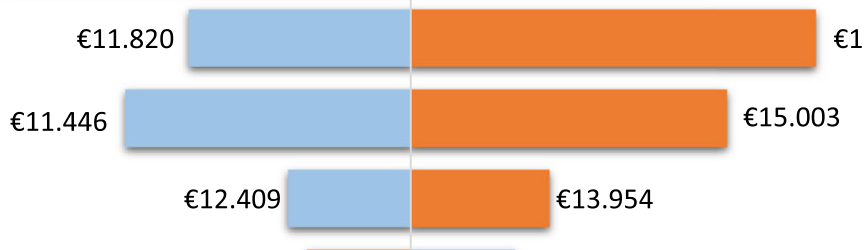

Overall cost of second-line treatments (detailed in figure $3 \mathrm{~b}$ )

Utility for PFS state

Prevalence of ALK+
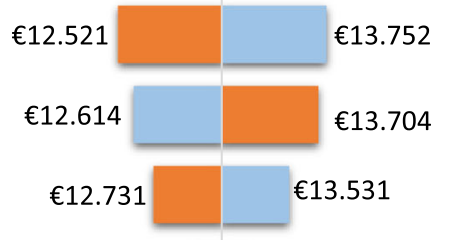

Administration cost

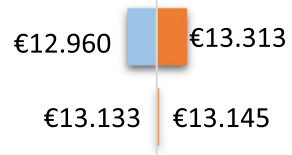

Probability of rebiopsy

Minimum Maximum

b) Detailed One-way sensitivy analysis results of second-line costs
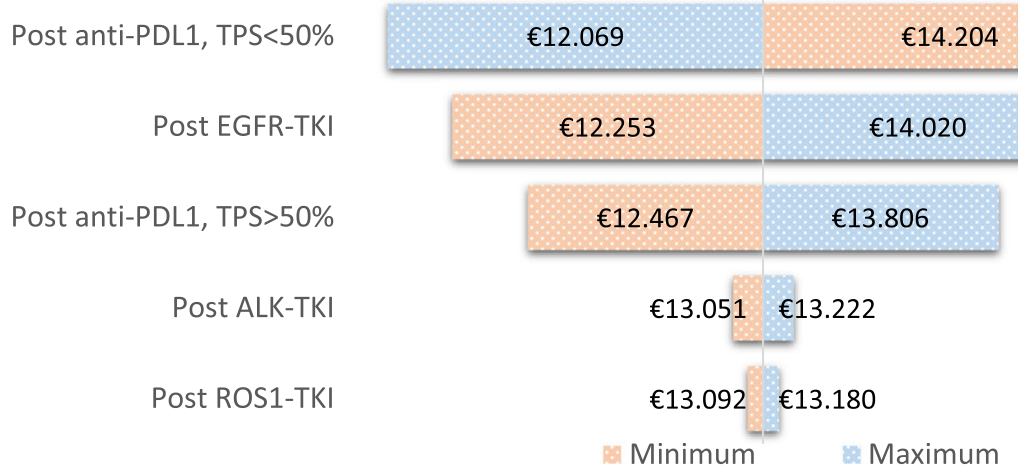

Fig. 3 Tornado diagrams. ICUR: incremental cost-utility ratio

compare between the current molecular testing scenario (considering 4 alternative strategies for $A L K$ rearrangement determination, IHC, FISH, reflex, and NGS) and the no-testing scenario. The ICER obtained (both base case and sensitive analysis) confirms that determining $A L K$ rearrangement in patients with advanced NSCLC is a cost-effective strategy, since it is below the costeffectiveness thresholds usually considered in Spain [50, 51]. Therefore, our findings support and confirm the recommendations of national guidelines [14]. Preliminary results of our study were presented in ISPOR 2020 in the form of poster [57] and 2020 World
Conference on Lung Cancer (WCLC) through an oral communication" [58].

The described comprehensive approach has also been used in other economic assessments. Lee et al. published a generalized model that allows the evaluation of molecular diagnosis and subsequent targeted therapy [59]. Using this generalized model, the same author determined the cost-benefit ratio of ALK testing using different techniques for subsequent targeted treatment with crizotinib. The authors concluded that more than $95 \%$ of the total cost corresponded to the treatment and, therefore, the model was particularly sensitive to the 
Table 5 Bivariate analysis

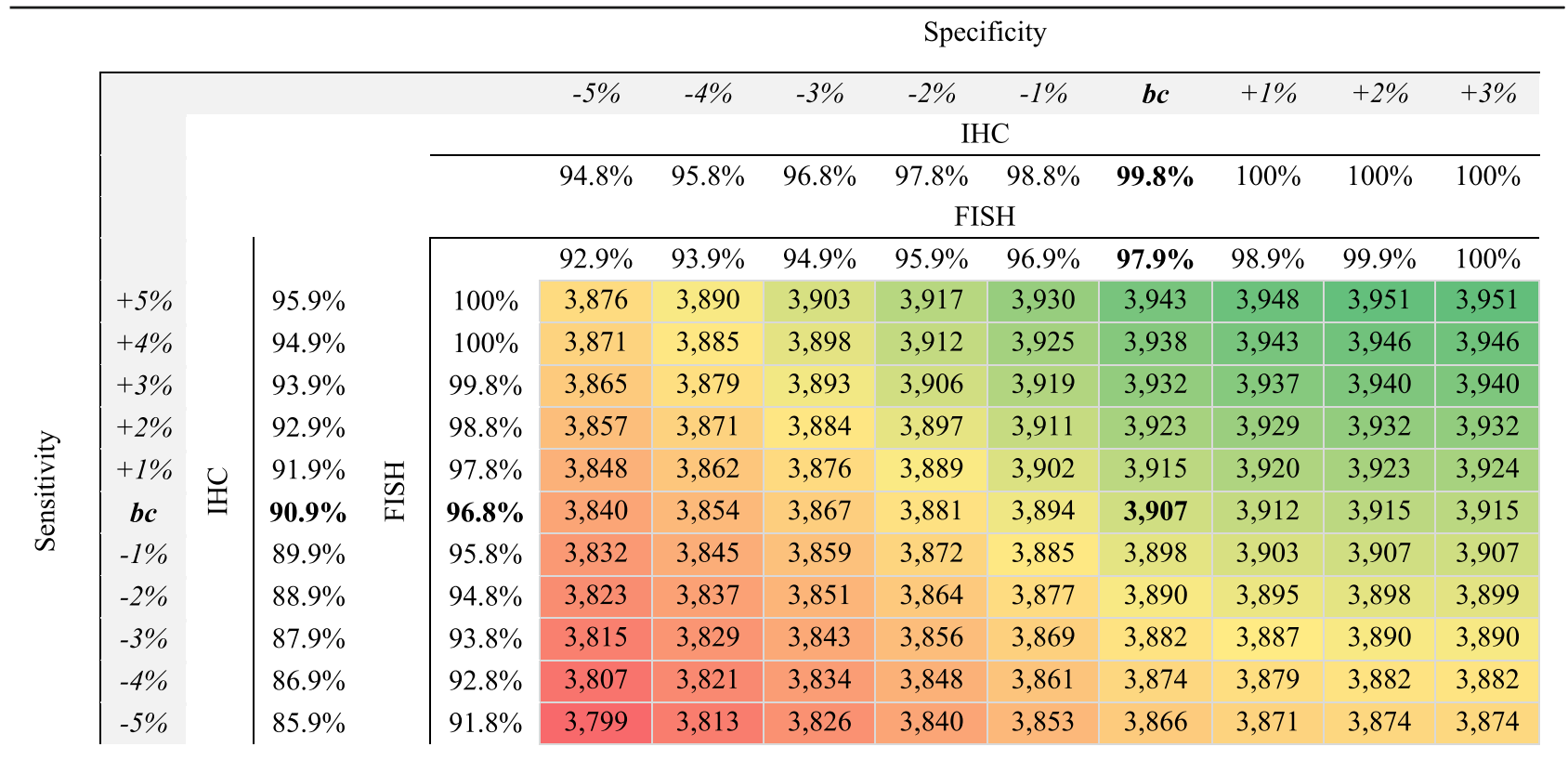

$B C$ Base case, IHC immunohistochemistry, FISH fluorescent in situ hybridizatio

price or clinical benefits of crizotinib and the accuracy of the diagnostic test, but was not particularly impacted by the cost of the diagnostic test [59].

Other studies have been based on similar approaches to compare $A L K$ rearrangement detection techniques. Doshi et al. [10] concluded that both in the United
States (U.S.) and Europe, $A L K$ testing only by IHC is the lower-cost strategy compared with using only FISH, reflex testing, or performing both tests in parallel. Paolini et al. [13] assessed the clinical and economic benefits of using IHC for $A L K$ rearrangement testing in Italy, and concluded that increased use of D5F3 would provide

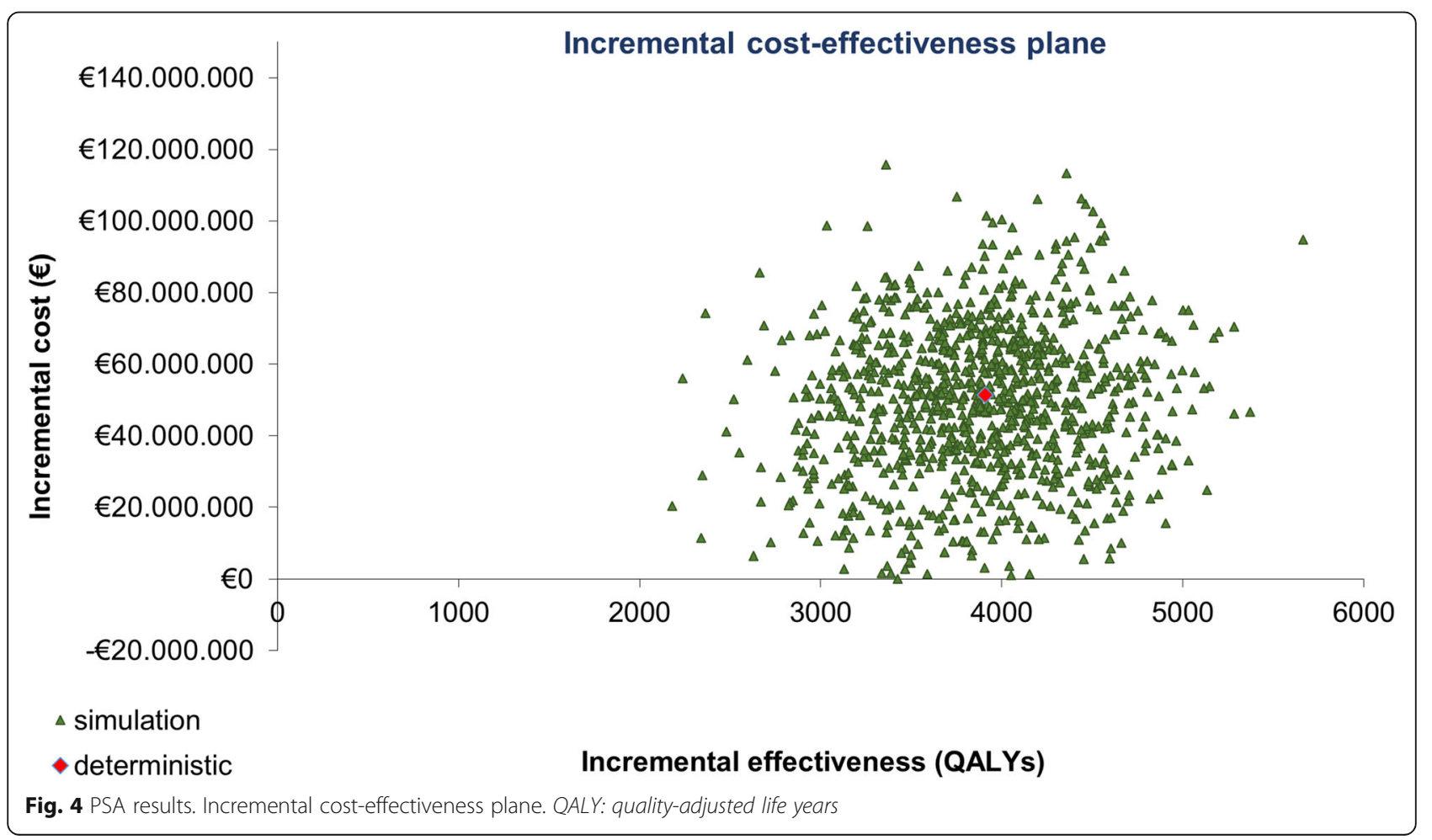


savings of $€ 468,000$, due to its lower acquisition cost compared with FISH and a comparable detection rate. Lu et al. [60] evaluate the cost-effectiveness of the ALK tests followed by crizotinib compared to the standard chemotherapy in advanced NSCLC from the Chinese healthcare system perspective. They found that two testing methods for ALK assessed (NGS and multiplex PCR) followed by subsequent crizotinib treatment, are both cost-effective compared to standard chemotherapy without ALK testing [60]. Also, two recent analyses have focused on the cost-effectiveness of using NGS in NSCLC patients, finding that this technology would be costeffective compared to single testing $[61,62]$.

Unlike these economic assessments, our analysis is not intended to compare diagnostic tests, the aim is to analyze the current scenario of molecular testing in Spain for patients with NSCLC, quantify the costs and long-term health outcomes, and compare them with a hypothetical non-testing scenario.

The study with the most similar objective was performed by Loubiére et al. [63], although the methodology differs entirely, as it prospectively evaluated a cohort of 843 patients in 19 French hospitals, while our analysis is based on a theoretical pharmacoeconomic model. Interestingly, their results were similar to our findings, since they reported that the "at least one biomarker status known" strategy is costeffective compared with the "no biomarker testing" strategy, with an ICER of $€ 13,230$ per QALY gained, while our base case ICER was 13,136 per QALY gained [63].

Our study has some limitations. First, the limitations inherent to pharmacoeconomic models, which are characterized by some degree of structural rigidity which cannot completely recapitulate the complexity of the clinical practice. For example, reproducing the pathological and molecular diagnosis process accurately is complicated, due to the complexity of the process and the high variability of the studies identified. Therefore, to simplify the model we did not include the preanalytic phases in our study. Although turnaround times are a key factor in initiating treatment at an appropriate time, no evidence has been found regarding their influence on the treatment effectiveness, and therefore the time from diagnosis to initiation of treatment was not included as a variable in our model. As stated in the literature and confirmed by the expert panel, turnaround times may vary from 2 to 5 [10] to 6-12 working days [64], with significant variations between centers (diagnostic outsourcing may add 1 week to the turnaround time according to the experts). A study designed to establish whether reducing the turnaround time could reduce the healthcare resources utilization and could improve the results obtained in this analysis would be of interest.
Secondly, in the molecular diagnosis phase, the percentage of invalid results and the specificity and sensitivity parameters of each technique were obtained from the literature, in the absence of a specifically designed study that could provide these data together. The definition of an invalid result may vary between studies and rely on the reference technique used to calculate the specificity and sensitivity. The studies published by Marchetti et al. [25, 26] were selected by the expert panel, since based on these parameters of specificity and sensitivity, the model predicted similar results to those observed in current clinical practice. Similarly, although the experts agreed that $2.6 \%$ of the invalid tests reported in LungPath study would apply equally to IHC and FISH, usual practice shows significant variations according to the histology and between reference and smaller centers, where preanalytical conditions may lead to a higher failure rate when using FISH. For NGS, a higher percentage of invalid results has been reported, as it is a newer technique and is of greater difficulty in the pre-analytic phase, and is more likely that samples will not have enough quantity or quality for NGS testing.

In addition, the percentage of invalid results could also be reduced in the future through the increased use of liquid biopsies. Liquid biopsy is a novel powerful tool for tumor genotyping and multiple levels of evidence support its use as an alternative strategy for molecular testing in advanced NSCLC, especially when tumor tissue is not sufficient [65].

Thirdly, the clinical management of patients with NSCLC reproduced by the Markov models also has some limitations. A lifetime horizon was adopted, as this made it possible to capture all the benefits of the targeted therapies in terms of LY and QALYs gained, in line with the economic evaluation developed by Lee et al. [57] which was based on the cost-effectiveness analysis of crizotinib. However, sensitivity analyses of the time horizon showed that determining $A L K$ rearrangement remained cost-effective as compared with the nontesting strategy. Due to the lack of individualized patient data for each treatment, the utilization of exponential parametric models (adjusted according to the median PFS and OS) was assumed. This assumption, validated by the panel of experts, is in line with published economic assessments of alectinib $[48,66]$, where the exponential models showed the best fit to the ALEX study data. Since our analysis focused on molecular testing of patients with advanced NSCLC and the consequent first-line of treatment, the subsequent lines (second-line) only show the influence in economic terms, were introduced in the model as a one-off cost.

Fourthly, concerning costs, it is difficult to set the real price of diagnostic tests, since there are wide variations 
between centers, and in many cases, the cost is borne by research funds or by pharmaceutical companies since they are not reimbursed by the Spanish National Health System. Besides, as the analysis focused on the determination of $A L K$, not all the benefits of using NGS, which allows to evaluate simultaneously multiple biomarkers instead of testing each biomarker one at a time, cannot be captured. An economic assessment of the use of NGS instead of testing individually the main biomarkers will require a specifically designed model and is beyond the scope of this work.

To overcome or minimize these limitations and the associated uncertainty, we performed sensitivity analyses that confirmed the robustness of the results obtained. In addition, all assumptions made, the parameters considered, and the results obtained were validated by the panel of experts.

\section{Conclusions}

In conclusion, our analysis shows that the detection of $A L K$ rearrangements in patients with NSCLC in Spain provides important clinical benefits compared with not testing in these patients. Appropriate $A L K$ testing yields about 4000 QALYs gained over a 20-year time horizon. When these results are compared with the incremental cost, the resulting ICER shows that the current molecular testing strategy in Spain not only increases and improves the lives of patients with NSCLC but is also cost-effective for the Spanish National Health System.

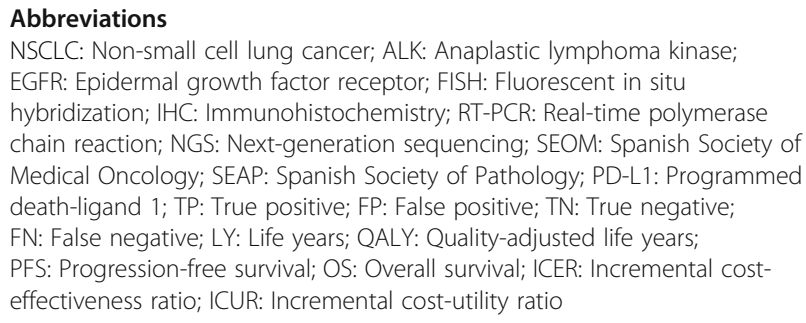

\section{Supplementary Information}

The online version contains supplementary material available at https://doi. org/10.1186/s12885-021-08407-1.

Additional file 1. Definition of subsequent (second-line) treatments.

\section{Acknowledgements}

Not applicable.

\section{Authors' contributions}

All authors contributed substantially to the development of the study. LrdA, PV, FG and DC designed the analysis. DC developed the model and wrote the first draft of the manuscript. ER, DB, ALO, HT and FR conformed the panel of experts that collected and validated the data inputs and participated in the interpretation of the results. All the authors read and approved the final manuscript.

Authors' information

Not applicable.

\section{Funding}

This study was funded by Roche Farma S.A. Roche Farma S. A played no role in the design of the study and collection, analysis, and interpretation of data and in writing the manuscript.

\section{Availability of data and materials}

Qualified researchers may request access to individual patient level data through the clinical study data request platform (https://vivli.org/). Further details on Roche's criteria for eligible studies are available here (https://vivli. org/members/ourmembers/). For further details on Roche's Global Policy on the Sharing of Clinical Information and how to request access to related clinical study documents, see here (https://www.roche.com/research_and_ development/who_we_are_how_we_work/clinical_trials/our_commitment_ to_data_sharing.htm).

\section{Declarations}

Ethics approval and consent to participate

Not applicable.

\section{Consent for publication}

Not applicable.

\section{Competing interests}

EN received research grant support from Pfizer, Merk Serono, BMS and Roche and participated in advisory boards from BMS, MSD, Lilly, Roche, Pfizer, Takeda, Boehringer Ingelheim, Amgen and AstraZeneca. FR received research grant support from Pfizer and Roche and received speaker or consulting fees from Roche, BMS, MSD, Merck, Novartis, Pfizer, AstraZeneca, Genomic Health, Bayer. LCG received speaker or consulting fees from Angelini, Grunenthal, Kyowa Kirin, Mudipharma, Pfizer, Roche, Rovi, Leo Pharma, Merck Serono, Ipsen Pharma, Lilly, Amgen, Boehringer Ingelheim, and AstraZeneca. DB. Received research support Roche and AstraZeneca and participated in advisory boards for MSD, Roche, AstraZeneca and Abbvie. HT received grants from Roche and AstraZeneca. ALO received fees for the participation in the study. LrdA, FG and PV are employees of Roche. DC is employee of Hygeia Consulting which received funding from Roche to conduct the analysis.

\section{Author details}

${ }^{1}$ Catalan Institute of Oncology, Hospital Duran i Reynals, IDIBELL, L'Hospitalet de Llobregat, Spain. ${ }^{2}$ Hospital Costa del Sol, Marbella, Spain. ${ }^{3}$ Hospital Universitario de Torrejón, Torrejón De Ardoz, Spain. ${ }^{4}$ Hospital Universitario de Jaen, Jaen, Spain. ${ }^{5}$ Hospital Universitario Central de Asturias, Oviedo, Spain. ${ }^{6}$ Hygeia Consulting S.A., Barcelona, Spain. ${ }^{7}$ Roche Farma S.A., Madrid, Spain. ${ }^{8}$ Hospital Universitario Fundacion Jimenez Diaz - CIBERONC, Madrid, Spain.

Received: 14 February 2021 Accepted: 25 May 2021

Published online: 10 June 2021

\section{References}

1. Hirsch F, Scagliotti G, Mulshine J, Kwon R, Curran W, Wu Y, et al. Lung cancer: current therapies and new targeted treatments. Lancet. 2017; 389(10066):299-311. https://doi.org/10.1016/S0140-6736(16)30958-8.

2. Las Cifras del Cáncer en España 2020. Seom web. https://seom.org/ seomcms/images/stories/recursos/Cifras_del_cancer_2020.pdf (2020). Accessed 05 June 2020

3. Planchard D, Popat S, Kerr K, Novello S, Smit E, Faivre-Finn C, et al. Metastatic non-small cell lung cancer: ESMO Clinical Practice Guidelines for diagnosis, treatment and follow-up. Ann Oncol. 2018;29:iv192-237. https:// doi.org/10.1093/annonc/mdy275.

4. Remon J, Besse B. Brain Metastases in Oncogene-Addicted Non-Small Cell Lung Cancer Patients: Incidence and Treatment. Front Oncol. 2018;8:88. https://doi.org/10.3389/fonc.2018.00088.

5. Zappa C, Mousa S. Non-small cell lung cancer: current treatment and future advances. Transl Lung Cancer Res. 2016;5(3):288-300. https://doi.org/10.2103 7/t|cr.2016.06.07.

6. Besse B, Adjei A, Baas P, Meldgaard P, Nicolson M, Paz-Ares L, et al. Panel Members ESMO. 2nd ESMO Consensus Conference on Lung Cancer: nonsmall-cell lung cancer first-line/second and further lines of treatment in 
advanced disease. Ann Oncol. 2014;25(8):1475-84. https://doi.org/10.1093/a nnonc/mdu123.

7. Mascaux C, Tomasini P, Greillier L, Barlesi F. Personalised medicine for nonsmall cell lung cancer. Eur Respir Rev. 2017;26(146):170066. https://doi. org/10.1183/16000617.0066-2017.

8. Sampsonas F, Ryan D, McPhillips D, Breen D. Molecular Testing and Personalized Treatment of Lung Cancer. Curr Mol Pharmacol. 2014;7(1):2232. https://doi.org/10.2174/187446720701150105171219.

9. Gregg J, Li T, Yoneda K. Molecular testing strategies in non-small cell lung cancer: optimizing the diagnostic journey. Transl Lung Cancer Res. 2019;8(3): 286-301. https://doi.org/10.21037/t|cr.2019.04.14.

10. Doshi S, Ray D, Stein K, Zhang J, Koduru P, Fogt F, et al. Economic analysis of alternative strategies for detection of ALK rearrangements in non small cell lung Cancer. Diagnostics. 2016;6(1):4. https://doi.org/10.3390/dia gnostics6010004.

11. Lin C, Shi X, Yang S, Zhao J, He Q, Jin Y, et al. Comparison of ALK detection by FISH, IHC and NGS to predict benefit from crizotinib in advanced nonsmall-cell lung cancer. Lung Cancer. 2019;131:62-8. https://doi.org/10.1016/j. lungcan.2019.03.018.

12. Evangelista A, Zanon M, Carloni A, de Paula F, Morini M, Ferreira-Neto M, et al. Detection of ALK fusion transcripts in FFPE lung cancer samples by NanoString technology. BMC Pulm Med. 2017;17(1). https://doi.org/10.1186/ s12890-017-0428-0.

13. Paolini D, Tiseo M, Demma F, Furneri G, Dionisi M, Akkermans M, et al. Ventana ALK (D5F3) in the detection of patients affected by anaplastic lymphoma kinase-positive non-small-cell lung Cancer: clinical and budget effect. Clin Lung Cancer. 2018;19(5):e735-43. https://doi.org/10.1016/j.cllc.2 018.05.012.

14. Garrido P, Conde E, de Castro J, Gómez-Román J, Felip E, Pijuan L, et al. Updated guidelines for predictive biomarker testing in advanced non-smallcell lung cancer: a National Consensus of the Spanish Society of Pathology and the Spanish Society of Medical Oncology. Clin Transl Oncol. 2020;22(7): 989-1003. https://doi.org/10.1007/s12094-019-02218-4.

15. Lee J, Tollefson E, Daly M, Kielb E. A generalized health economic and outcomes research model for the evaluation of companion diagnostics and targeted therapies. Expert Rev Pharmacoecon Outcomes Res. 2013;13(3): 361-70. https://doi.org/10.1586/erp.13.23.

16. López-Bastida J, Oliva J, Antoñanzas F, García-Altés A, Gisbert R, Mar J, et al. Propuesta de guía para la evaluación económica aplicada a las tecnologías sanitarias. Gac Sanit. 2010;24(2):154-70. https://doi.org/10.1 016/j.gaceta.2009.07.011.

17. Puig-Junoy J, Oliva-Moreno J, Trapero-Bertrán M, et al. y Servei Català de la Salut (CatSalut). In: Guía y recomendaciones para la realización y presentación de evaluaciones económicas y análisis de impacto presupuestario de medicamentos en el ámbito del CatSalut. Barcelona: Generalitat de Catalunya; 2014.

18. Globocan. Global Cancer Observatory web. https://gco.iarc.fr/ 2020. Acessed 1 Junio 2020.

19. Vidal J, Clavé S, de Muga S, González I, Pijuan L, Gimeno J, et al. Assessment of ALK status by FISH on 1000 Spanish non-small cell lung cancer patients. J Thorac Oncol. 2014;9(12):1816-20. https://doi.org/10.1097/JTO. 0000000000000361.

20. Provencio M, Carcereny E, Rodríguez-Abreu D, López-Castro R, Guirado M, Camps C, et al. Lung cancer in Spain: information from the thoracic tumors registry (TTR study). Transl Lung Cancer Res. 2019;8(4):461-75. https://doi. org/10.21037/tlcr.2019.08.05.

21. de Castro J, Tagliaferri P, de Lima V, Ng S, Thomas M, Arunachalam A, et al. Systemic therapy treatment patterns in patients with advanced non-small cell lung cancer (NSCLC): PIvOTAL study. Eur J Cancer Care (Engl). 2017; 26(6):e12734. https://doi.org/10.1111/ecc.12734.

22. López J, Alexandre L, Caldero S, Gonzales A, Lopez P, Bellvert C, et al. EP1. 09-17 Spanish Lung Cancer Biomarker Testing Registry (Lungpath): Descriptive Analysis Focus in ALK Traslocation Results. J Thorac Oncol. 2019; 14(10):S1004-5. https://doi.org/10.1016/j.tho.2019.08.2213.

23. Volckmar A, Leichsenring J, Kirchner M, Christopoulos P, Neumann O, Budczies J, et al. Combined targeted DNA and RNA sequencing of advanced NSCLC in routine molecular diagnostics: analysis of the first 3,000 Heidelberg cases. Int J Cancer. 2019;145(3):649-61. https://doi.org/10.1002/ ijc.32133.

24. Chouaid, C., Dujon, C., Do, P., Monnet, I., Madroszyk, A., Le Caer H. et al. Feasibility and clinical impact of re-biopsy in advanced non small-cell lung cancer: A prospective multicenter study in a real-world setting (GFPC study 12-01). Lung Cancer. 86(2):170-173(2014). doi: https://doi.org/10.1016/j. lungcan.2014.08.016

25. Marchetti A, Di Lorito A, Pace M, lezzi M, Felicioni L, D'Antuono T, et al. ALK protein analysis by $\mathrm{IHC}$ staining after recent regulatory changes: a comparison of two widely used approaches, revision of the literature, and a new testing algorithm. J Thorac Oncol. 2016;1 1(4):487-95. https://doi.org/1 0.1016/j.jtho.2015.12.111.

26. Marchetti A, Ardizzoni A, Papotti M, Crinò L, Rossi G, Gridelli C, et al. Recommendations for the analysis of ALK gene rearrangements in nonsmall-cell lung Cancer: a consensus of the Italian Association of Medical Oncology and the Italian Society of Pathology and Cytopathology. J Thorac Oncol. 2013;8(3):352-8. https://doi.org/10.1097/JTO.0b013e3182 $7 \mathrm{~d} 5280$.

27. Gisbert, R., Brosa, M. Oblikue Consulting, S.L. Healthcare Costs Database: eSalud web http://www.oblikue.com/bddcostes/. Accessed in 25 May 2020.

28. Mok T, Camidge DR, Gadgeel SM, Rosell R, Dziadziuszko R, Kim DW, et al. Updated overall survival and final progression-free survival data for patients with treatment-naïve advanced ALK-positive non-small-cell lung cancer in the ALEX study. Ann Oncol. 2020;31(8):1056-64. https://doi.org/10.1016/j.a nnonc.2020.04.478.

29. Soria JC, Ohe Y, Vansteenkiste J, Reungwetwattana T, Chewaskulyong B, Lee $\mathrm{KH}$, et al. FLAURA Investigators. Osimertinib in Untreated EGFR-Mutated Advanced Non-Small-Cell Lung Cancer. N Engl J Med. 2018;11(378(2)):11325. https://doi.org/10.1056/NEJMoa1713137.

30. Ramalingam SS, Vansteenkiste J, Planchard D, Cho BC, Gray JE, Ohe Y, et al. Overall Survival with Osimertinib in Untreated, EGFR-Mutated Advanced NSCLC. N Engl J Med. 2020;382(1):41-50. https://doi.org/10.1056/NEJMoa1 913662

31. Shaw AT, Riely GJ, Bang YJ, Kim DW, Camidge DR, Solomon BJ, et al. Crizotinib in ROS1-rearranged advanced non-small-cell lung cancer (NSCLC): updated results, including overall survival, from PROFILE 1001. Ann Oncol. 2019;30(7):1121-6. https://doi.org/10.1093/annonc/mdz131.

32. Reck M, Rodríguez-Abreu D, Robinson AG, Hui R, Csőszi T, Fülöp A, et al. Pembrolizumab versus chemotherapy for PD-L1-positive non-small-cell lung cancer. N Engl J Med. 2016;375(19):1823-33. https://doi.org/10.1056/ NEJMoa1606774.

33. Reck M, Rodríguez-Abreu D, Robinson AG, Hui R, Csőszi T, Fülöp A, et al. Updated Analysis of KEYNOTE-024: Pembrolizumab Versus Platinum-Based Chemotherapy for Advanced Non-Small-Cell Lung Cancer With PD-L1 Tumor Proportion Score of 50\% or Greater. J Clin Oncol. 2019;37(7):537-46. https://doi.org/10.1200/JCO.18.00149.

34. Paz-Ares LG, de Marinis F, Dediu M, Thomas M, Pujol JL, Bidoliet P, et al. PARAMOUNT: Final Overall Survival Results of the Phase III Study of Maintenance Pemetrexed Versus Placebo Immediately After Induction Treatment With Pemetrexed Plus Cisplatin for Advanced Nonsquamous Non-Small-Cell Lung Cancer. J Clin Oncol. 2013;31(23):2895-902. https://doi. org/10.1200/JCO.2012.47.1102.

35. Sandler A, Gray R, Perry MC, Brahmer J, Schiller JH, Dowlati A, et al. Paclitaxelcarboplatin alone or with bevacizumab for non-smallcell lung cancer. N Engl J Med. 2006;355(24):2542-50. https://doi.org/10.1056/NEJMoa061884.

36. Gandhi L, Rodríguez-Abreu D, Gadgeel S, Esteban E, Felip E, De Angelis F, et al. Pembrolizumab plus chemotherapy in metastatic non-small-cell lung Cancer. N Engl J Med. 2018;378(22):2078-92. https://doi.org/10.1056/ NEJMoa1801005.

37. Gadgeel S, Rodríguez-Abreu D, Speranza G, Esteban E, Felip E, Dómine M, et al. Updated analysis from KEYNOTE-189: Pembrolizumab or placebo plus Pemetrexed and platinum for previously untreated metastatic nonsquamous non-small-cell lung Cancer. J Clin Oncol. 2020;9(14): JCO1903136. https://doi.org/10.1200/JCO.19.03136.

38. General Council of the Association of Official Pharmacists. General Council of the Association of Official Pharmacists Database: Bot PLUS 2.0 web. https://botplusweb.portalfarma.com/. Accessed in September 2020.

39. Royal Decree-Law 8/2010. Extraordinary measures to reduce the public deficit. Boe web. http://www.boe.es/boe/dias/2010/05/24/pdfs/BOE-A-20108228.pdf (2010) Accessed in September 2020.

40. National Health Survey of Spain. MSCBS web. https://www.mscbs.gob.es/ estadEstudios/estadisticas/encuestaNacional/encuesta2017.htm (2018) Accessed 26 May 2020.

41. Novello S, Mazières J, Oh I, de Castro J, Migliorino M, Helland Å, et al. Alectinib versus chemotherapy in crizotinib-pretreated anaplastic lymphoma 
kinase (ALK)-positive non-small-cell lung cancer: results from the phase III ALUR study. Ann Oncol. 2018;29(6):1409-16. https://doi.org/10.1093/annonc/ mdy 121.

42. Ahn MJ, Tsai CM, Shepherd FA, Bazhenova L, Sequist LV, Hida T. Osimertinib in patients with T790M mutation-positive, advanced non-small cell lung cancer: Long-term follow-up from a pooled analysis of 2 phase 2 studies. Cancer. 2019;125(6):892-901. https://doi.org/10.1002/cncr.31891.

43. Masuda T, Imai H, Kuwako T, Miura Y, Yoshino R, Kaira K, et al. Efficacy of platinum combination chemotherapy after first-line gefitinib treatment in non-small cell lung cancer patients harboring sensitive EGFR mutations. Clin Transl Oncol. 2015;17(9):702-9. https://doi.org/10.1007/s12094-015-1297-8.

44. Zhang L, Jiang T, Zhao C, Li W, Li X, Zhao S, et al. Efficacy of crizotinib and pemetrexed-based chemotherapy in Chinese NSCLC patients with ROS1 rearrangement. Oncotarget. 2016;7(46):75145-54. https://doi.org/10.18632/ oncotarget.12612.

45. Li T, Piperdi B, Walsh WV, Kim M, Beckett LA, Gucalp R, et al. Randomized phase 2 trial of Pharmacodynamic separation of Pemetrexed and intercalated Erlotinib versus Pemetrexed alone for advanced nonsquamous, Non-small-cell Lung Cancer. Clinical Lung Cancer. 2017;18(1):60-7. https:// doi.org/10.1016/j.cllc.2016.10.003.

46. Chen $R$, Tao $Y$, Xu X, Shan $L$, Jiang $H$, Yin $Q$, et al. The efficacy and safety of nivolumab, pembrolizumab, and atezolizumab in treatment of advanced non-small cell lung cancer. Discov Med. 2018;26(143):155-66.

47. Reck, M., Kaiser, R., Mellemgaard, A., Douillard, J.Y., Orlov, S., Krzakowski, M., von Pawel J., Gottfried M., Bondarenko I., Liao M., Gann C.N., Barrueco J., Gaschler-Markefski B., Novello S., LUME-Lung 1 Study Group. Docetaxel plus nintedanib versus docetaxel plus placebo in patients with previously treated non-small-cell lung cancer (LUME-lung 1): a phase 3, double-blind, randomised controlled trial. Lancet Oncol 15(2):143-155 (2014). doi: https:// doi.org/10.1016/S1470-2045(13)70586-2

48. Carlson J, Suh K, Orfanos P, Wong W. Cost effectiveness of Alectinib vs. Crizotinib in First-Line Anaplastic Lymphoma Kinase-Positive Advanced NonSmall-Cell Lung Cancer. Pharmacoeconomics. 2018;36(4):495-504. https:// doi.org/10.1007/s40273-018-0625-6.

49. Briggs A. Handling uncertainty in cost-effectiveness models. Pharmacoeconomics. 2000;17(5):479-500. https://doi.org/10.2165/0001 9053-200017050-00006.

50. Vallejo-Torres L, García-Lorenzo B, Serrano-Aguilar P. Estimating a costeffectiveness threshold for the Spanish NHS. Health Econ. 2018;27(4):746-61. https://doi.org/10.1002/hec.3633.

51. Sacristán J, Oliva J, Campillo-Artero C, Puig-Junoy J, Pinto-Prades J, Dilla T, et al. ¿Qué es una intervención sanitaria eficiente en España en 2020? Gac Sanit. 2020;34(2):189-93. https://doi.org/10.1016/j.gaceta.2019.06.007.

52. Gómez J, de Castro J, Concha Á, Felip E, Isla D, López-Ríos F, et al. Recomendaciones para la determinación de biomarcadores en el carcinoma de pulmón no microcítico avanzado. Consenso nacional de la Sociedad Española de Anatomía Patológica y de la Sociedad Española de Oncología Médica. Rev Esp Patol. 2012;45(1):14-28. https://doi.org/10.1016/j.patol.201 9.11.004.

53. Elliott J, Bai Z, Hsieh SC, Kelly SE, Chen L, Skidmoreet B, et al. ALK inhibitors for non-small cell lung cancer: A systematic review and network metaanalysis. PLoS One. 2020;15(2):e0229179. https://doi.org/10.1371/journal. pone.0229179.

54. Lindeman N, Cagle P, Aisner D, Arcila M, Beasley M, Bernicker E, et al. Updated molecular testing guideline for the selection of lung Cancer patients for treatment with targeted tyrosine kinase inhibitors: guideline from the College of American Pathologists, the International Association for the Study of Lung Cancer, and the Association for Molecular Pathology. Arch Pathol Lab Med. 2018;142(3):321-46. https://doi.org/10. 5858/arpa.2017-0388-CP.

55. Majem M, Juan O, Insa A, Reguart N, Trigo J, Carcereny E, et al. SEOM clinical guidelines for the treatment of non-small cell lung cancer (2018). Clin Transl Oncol. 2018;21(1):3-17. https://doi.org/10.1007/s12094018-1978-1.

56. Peters S, Camidge DR, Shaw AT, Gadgee S, Ahn JS, Kim DW, et al. Alectinib versus Crizotinib in untreated ALK-positive non-small-cell lung Cancer. N Engl J Med. 2017;377(9):829-38. https://doi.org/10.1056/NEJMoa1704795.

57. Carcedo D., Bautista D., Ortega A. L, Rojo F., Cabezon-Gutierrez L., Torres H., et al. PCN95 clinical and economic IMPACT of ALK rearrangement testing in advanced NSCLC in Spain compared with a hypothetical NO-testing scenario. Value Health 2020;23:S439, DOI: https://doi.org/10.1016/j.jval.2020.08.232.

58. Gutiérrez LC, Torres H, Nadal E, Bautista D, Granados ALO, Rojo F, et al. $1361 \mathrm{P}$ determination of ALK rearrangements in non-small cell lung cancer: clinical and economic impact of current practice in Spain. Ann Oncol. 2020; 31:S870-1. https://doi.org/10.1016/j.annonc.2020.08.1675.

59. Lee JA, Bubendorf $L$, Stahel R, Peters S. Testing for anaplastic lymphoma kinase rearrangement to target Crizotinib therapy: oncology, Pathology and Health Economic Perspectives. Expert Rev Anticancer Ther. 2013;13(5):62536. https://doi.org/10.1586/era.13.42.

60. Lu S, Yu Y, Fu S, Ren H. Cost-effectiveness of ALK testing and first-line crizotinib therapy for non-small-cell lung cancer in China. PLoS One. 2018; 13(10):e0205827. https://doi.org/10.1371/journal.pone.0205827.

61. Tan AC, Lai GGY, Tan GS, Poon SY, Doble B, Lim TH, et al. Utility of incorporating next-generation sequencing (NGS) in an Asian non-small cell lung cancer (NSCLC) population: incremental yield of actionable alterations and cost-effectiveness analysis. Lung Cancer. 2020;139:207-15. https://doi. org/10.1016/j.lungcan.2019.11.022.

62. Pennell NA, Mutebi A, Zhou Z, Ricculli ML, Tang W, Wang H, et al. Economic impact of next-generation sequencing versus single-gene testing to detect genomic alterations in metastatic non-small-cell lung Cancer using a decision analytic model. JCO Precision Oncology. 2019;3(3):1-9. https://doi. org/10.1200/PO.18.00356

63. Loubière S, Barlesi F, Missy P, Morin F, Auquier P, Cadranel J. Costeffectiveness of biomarker testing for treatment choices in advanced nonsmall cell lung carcinoma: impact of diagnostic strategies and their turnaround times. Eur Respir J. 2018;51(6):1800844. https://doi.org/10.11 83/13993003.00844-2018.

64. Illei P, Wong W, Wu N, Chu L, Gupta R, Schulze K, et al. ALK testing trends and patterns among community practices in the United States. JCO Precision Oncol. 2018;2(2):1-11. https://doi.org/10.1200/PO.18.00159.

65. Russo A, De Miguel Perez D, Gunasekaran M, Scilla K, Lapidus R, Cooper B, et al. Liquid biopsy tracking of lung tumor evolutions over time. Expert Rev Mol Diagn. 2019 Dec;19(12):1099-108. https://doi.org/10.1080/14737159.202 0.1680287.

66. Dental and Pharmaceutical Benefits Agency (TLV), Main Association of Austrian Social Security Institutions (HVB), Agency for Quality and Accreditation in Health Care and Social Welfare (AAZ). Rapid assessment on pharmaceutical technologies using the HTA Core Model for Rapid Relative Effectiveness Assessment. Alectinib as monotherapy for the first-line treatment of adult patients with ALK-positive advanced non-small cell lung cancer. EUnetHTA web. https://www.eunethta.eu/wp-content/uploads/2018/01/PTJA03-AlectinibFinal-Assessment-Report.pdf (2018). Accessed 26 May 2020

\section{Publisher's Note}

Springer Nature remains neutral with regard to jurisdictional claims in published maps and institutional affiliations.

Ready to submit your research? Choose BMC and benefit from

- fast, convenient online submission

- thorough peer review by experienced researchers in your field

- rapid publication on acceptance

- support for research data, including large and complex data types

- gold Open Access which fosters wider collaboration and increased citations

- maximum visibility for your research: over $100 \mathrm{M}$ website views per year

At BMC, research is always in progress.

Learn more biomedcentral.com/submissions 